\title{
Computer-Controlled Voltage/Current Source and Response Monitoring System for Electrochemical Investigations
}

\author{
Zoran Stevic ${ }^{1}$, Misa Stevic ${ }^{2}$, Ilija Radovanovic ${ }^{3}$, Predrag Stolic ${ }^{4}$, Milos Milesevic $^{5}$, Milos Marjanovic $^{6}$, \\ Milan Radivojevic ${ }^{7}$, Sanja Petronic ${ }^{8}$ \\ ${ }^{1}$ University of Belgrade, Technical faculty Bor, School of Electrical Engineering; \\ ${ }^{2}$ Elsys, Belgrade \\ ${ }^{3}$ School of Electrical Engineering, University of Belgrade, Innovation Center of School of Electrical \\ Engineering in Belgrade, Serbia \\ ${ }^{4}$ University of Belgrade, Technical Faculty Bor \\ ${ }^{5}$ School of Electrical Engineering, University of Belgrade \\ ${ }^{6}$ MS Kablovi, Paracin, Serbia \\ ${ }^{7}$ Mining and Metallurgy Institute Bor, Bor, Serbia \\ ${ }^{8}$ The Academy of Applied Technical Studies Belgrade, Katarine Ambrozic 3, Belgrade, Serbia \\ *E-mail: zstevic@ @tfbor.bg.ac.rs
}

doi: 10.20964/2021.06.04

Received: 28 January 2020 / Accepted: 26 March 2021 / Published: 30 April 2021

In this paper, a computer-controlled voltage and current source, together with aresponse monitoring system for electrochemical investigations, is presented. The measuring system consisted of two major parts: the measuring hardware (HW) and the proprietary software. The hardware included the data acquisition USB card NI USB 6211 from National Instruments Company as well as all needed circuits (the analogue front end, the signal conditioning circuits, and power supplies). The software is based on the LabVIEW platform from National Instruments, and it is designed to control the signal generation and measurements, to cancel the noise in the signals, and to calibrate the device. The supported electrochemical methods are potential, potentiostatic and galvanostatic measurements, as well as the cyclic voltammetry and impedance measurments. The system was thoroughly tested, and it was determined that the system characteristics fulfil the requirements for most of the electrochemical and bioelectrochemical measurements, supercapacitor characteristics investigations, and much more. The overall system is modular; the HW and SW can easily be upgraded to support different methods and purposes and, therefore, the performance of the system.

Keywords: electrochemical instrumentation, LabVIEW, computer-controlled voltage/current source, computer measurement, Electrochemical Impedance Spectroscopy 


\section{FULL TEXT}

(C) 2021 The Authors. Published by ESG (www.electrochemsci.org). This article is an open access article distributed under the terms and conditions of the Creative Commons Attribution license (http://creativecommons.org/licenses/by/4.0/). 